\title{
Spatially deranged though temporally correct expression of a Strongylocentrotus purpuratus actin gene fusion in transgenic embryos of a different sea urchin family
}

\author{
Roberta R. Franks, Barbara R. Hough-Evans, Roy J. Britten, and Eric H. Davidson \\ Division of Biology, California Institute of Technology, Pasadena, California 91125 USA
}

\begin{abstract}
We report the unexpected observation that cis-regulatory sequences of a Strongylocentrotus purpuratus actin gene, which direct a particular, lineage-specific pattern of embryonic expression, confer a completely different spatial pattern of expression when introduced into embryos of another sea urchin species. We utilized a fusion gene construct in which the bacterial chloramphenicol acetyl transferase (CAT) reporter gene is driven by CyIIIa actin regulatory sequences. We previously showed that the regulatory region that is included suffices to promote the accumulation of CAT mRNA in transgenic S. purpuratus embryos, on the same developmental schedule and in the same embryonic region, the aboral ectoderm, in which the CyIIIa actin gene is normally expressed (Flytzanis et al. 1987; Hough-Evans et al. 1987). When injected into zygotes of Lytechinus variegatus, which belongs to a different echinoid family, the expected temporal pattern of expression of CAT enzyme was observed. Thus, in both $S$. purpuratus and $L$. variegatus embryos, expression is activated at the early blastula stage, although this stage is attained several hours sooner in $L$. variegatus embryo cultures. Similar kinetics of CAT enzyme accumulation were obtained whether the gene was introduced directly into the $L$. variegatus zygote nucleus or into the cytoplasm. However, when examined by in situ hybridization, the transgenic $L$. variegatus embryos were found to display a totally new pattern of CAT mRNA accumulation. Copious CAT transcripts were detected not only in aboral ectoderm cells, but also in skeletogenic mesenchyme cells, gut cells, and oral ectoderm, all cell types that in the transgenic $S$. purpuratus controls are invariably devoid of detectable CAT transcripts.
\end{abstract}

[Key Words: Gene transfer; early development; CyIIIa actin gene; spatial regulation; temporal regulation] Received September 18, 1987; revised version accepted November 12, 1987.

The aboral ectoderm of the sea urchin embryo is constructed of six functionally equivalent clones of cells, the individual progenitors of which segregate from other lineages at the $3 \mathrm{rd}, 5 \mathrm{th}$, and 6 th cleavages (Davidson 1986; Cameron et al. 1987; R. Cameron, S. Fraser, and E. Davidson, unpubl.). By the 7 th -8 th cleavage these clones have initiated a specific, spatially confined program of gene expression, which is maintained, and later augmented, during the normal differentiation of the aboral ectoderm. Among the genes expressed only in aboral ectoderm are the CyIIIa and CyIIIb cytoskeletal actin genes (Angerer and Davidson 1984; Cox et al. 1986; Lee 1986; Lee et al. 1986); the Specl gene, which codes for a $\mathrm{Ca}^{2+}$-binding protein belonging to the troponin C superfamily; and a set of several related Spec 2 genes (Bruskin et al. 1981, 1982; Lynn et al. 1983; Carpenter et al. 1984). For present purposes it is necessary to note that though the canonical cell lineage, the morpho- logical structure of the embryo, and presumably the function of aboral ectoderm cells appear similar in all regularly developing echinoid species, most of the molecular evidence pertaining to specific aboral ectoderm gene functions derives from studies on Strongylocentrotus purpuratus embryos. In particular, the existence in other species of cytoskeletal actin genes expressed exclusively in aboral ectoderm, as are the CyIIIa and CyIIIb genes of $S$. purpuratus has not been ascertained, because the diagnostic $3^{\prime}$ trailer sequences specific to the mRNAs of these genes do not cross-react except within the genus Strongylocentrotus (Lee et al. 1984). However, Spec proteins have been demonstrated immunocytologically to be confined to the aboral ectoderm of Lytechinus pictus embryos (W. Klein, pers. comm.). This result per se implies the presence of a similar aboral ectoderm-specific program of gene expression in the genus Lytechinus, an important argument for what follows. $L$. 
variegatus and $S$. purpuratus are phylogenetically rather distant members of the order Echinoida, belonging, respectively, to the families Toxopneustidae and Strongylocentrotidae (Jensen 1981). These groups are believed to have last shared common ancestors more than $40 \mathrm{mil}$ lion years ago (A. Smith, pers. comm.). The genomes of $L$. pictus and $S$. purpuratus have diverged significantly since separation, and only $10-15 \%$ cross reaction of total single-copy sequence is observed even under relatively relaxed criterion conditions (Angerer et al. 1976; Hall et al. 1980; Grula et al. 1982).

Gene transfer, deletion, and in vivo DNA competition studies have shown that cis-regulatory sequences both necessary and sufficient for correct temporal and spatial CyIIIa actin gene expression are located within a 2500nucleotide sequence upstream of the transcription start site (Davidson et al. 1985; Flytzanis et al. 1987; HoughEvans et al. 1987; R. Franks and E. Davidson, in prep.). This sequence includes eight distinct regions where DNA-protein interactions occur, the specificity of which is manifested in vitro by their $10^{4}$ - to $10^{6}$-fold preferences for the respective CyIIIa sequences, relative to various DNA copolymers, or to naturally occurring DNA carriers (F. Calzone, N. Thézé, P. Thiebaud, R. Britten, and E. Davidson, in prep.). The functional significance of these cis-regulatory sequences has been established by gene transfer experiments, in which a fusion gene construct containing the bacterial chloramphenicol acetyl transferase (CAT) reporter gene under the control of these sequences is injected into $S$. purpuratus egg cytoplasm. Linear DNA molecules thus introduced are rapidly ligated into random end-to-end concatenates, and are efficiently incorporated into one or several blastomere nuclei during cleavage. They then undergo many rounds of replication along with the endogenous embryo genomes, and are retained stably thereafter for the life of the cell lineage(s) in which they are incorporated (Flytzanis et al. 1985; McMahon et al. 1985; Franks et al. 1987). Flytzanis et al. (1987) showed that $S$. purpuratus embryos bearing the CyIIIa - CAT construct activate the synthesis of CAT enzyme protein at about the same time as normal embryos activate their CyIIIa genes. Furthermore, the CyIIIa - CAT construct is expressed only in the correct cells. Thus, although the mosaic pattern of exogenous DNA incorporation may result in the occurrence of CyIIIa - CAT DNA in gut cells, primary and secondary mesenchyme cells, and oral ectoderm, as well as in aboral ectoderm, CAT mRNA is detectable by in situ hybridization exclusively in aboral ectoderm cells (Hough-Evans et al. 1987; this paper; R. Franks and B. Hough-Evans, unpubl.).

The present work developed from an inquiry into the consequences of direct introduction of exogenous DNA into the zygote nucleus, rather than into the unfertilized egg cytoplasm. For this study we again utilized the $S$. purpuratus CyIIIa . CAT construct, but to visualize the target nuclei, the DNA was injected into the nearly transparent eggs of another sea urchin species, $L$. variegatus. We have reported elsewhere the fate of this exogenous DNA in $L$. variegatus embryos, larvae, and post- metamorphosis juveniles that were raised from zygotes into which this DNA had been injected in either the nucleus, or for comparison, the cytoplasm (Franks et al. 1987). In this paper we focus specifically on the embryonic expression of CAT mRNA and enzyme protein. It suffices to note that Franks et al. (1987) found very little difference in the extent or rate of exogenous DNA replication during embryogenesis, comparing nuclear and cytoplasmic injection samples, though large differences appeared at later stages, due apparently to an enhanced probability of wider distribution of the exogenous DNA among diverse cell lineages after nuclear injection. We show here that in either nuclear or cytoplasmic $L$. variegatus injection samples, the CyIIIa CAT gene is activated at the expected developmental stage, equivalent to that at which it (or the CyIIIa actin gene itself) begins to be expressed in S. purpuratus embryos. However, to our considerable surprise we discovered that the spatial regulation of the CyIIIa - CAT construct is abolished in $L$. variegatus host embyros, in that CAT mRNA accumulation is no longer confined to cells of the aboral ectoderm, or indeed to any particular cell lineage.

\section{Results}

\section{Temporal regulation of the CyIIIa $\cdot$ CAT fusion gene} injected into $\mathrm{L}$. variegatus egg cytoplasm

At the $23^{\circ} \mathrm{C}$ culture temperature embryos of $L$. variegatus develop noticeably more rapidly than do $S$. purpuratus embryos, which in our laboratory are grown at $16^{\circ} \mathrm{C}$. Normal $S$. purpuratus embryos at the latter temperature activate the aboral ectoderm-specific CyllIa actin gene at $12-14 \mathrm{hr}$ postfertilization (Shott et al. 1984; Lee 1986; Lee et al. 1986). An initial series of experiments was designed to determine whether expression of CAT enzyme from the CyIIIa . CAT fusion construct would be activated at the equivalent stage of development when introduced into $L$. variegatus eggs. That is, the expected stage of CAT enzyme appearance in transgenic $L$. variegatus embryos would be the early blastula, when the embryo has completed about eight cleavage divisions. According to the cell number data of Franks et al. (1987), this stage is attained at approximately $7 \mathrm{hr}$ postfertilization in control $L$. variegatus at $23^{\circ} \mathrm{C}$, and it might be expected to occur up to $1 \mathrm{hr}$ later in embryos developing from injected eggs, due to a slight delay in the initiation of cleavage following the injection trauma.

A map of the CyIIIa - CAT fusion construct displaying its essential components is shown in Figure la. This construct was linearized at the SphI site (circled), and injected into the cytoplasm of $L$. variegatus zygotes. As established in the previous study, injected linear DNA undergoes essentially the same process of amplification during development in this species as in $S$. purpuratus (Franks et al. 1987). Thus, in a large fraction of embryos the concatenated exogenous DNA molecules are incorporated into one or more nuclei during the first several cleavages. These concatenates then rapidly associate in 

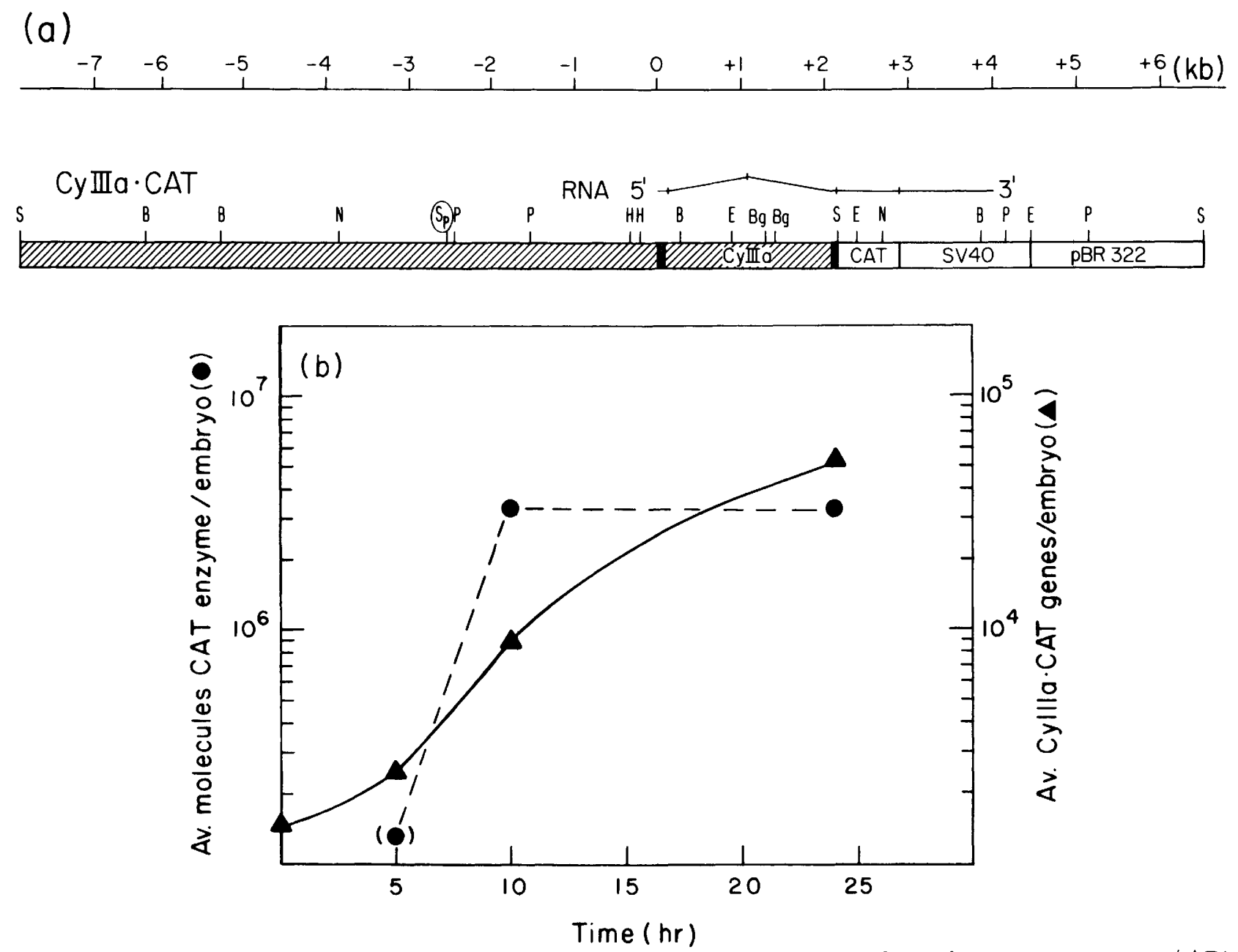

Figure 1. Temporal regulation of $S$. purpuratus CyIIIa - CAT fusion gene injected into cytoplasm of $L$. variegatus zygotes. (a) Diagram of the CyIIIa - CAT fusion gene. Hatched areas represent $S$. purpuratus sequences, including a 2.2-kb leader intron contained within the CyIIIa primary transcript (Akhurst et al. 1987). The fusion point is a Sall site located 11 codons following the start codon of the CyIIIa - CAT message (see Davidson et al. 1985; Flytzanis et al. 1987 for details of CyIIIa - CAT construction). The CyIIIa - CAT construct also contains an SV40 poly(A) addition site and pBR322 plasmid sequences. The SphI site (circled) was used for linearization of the fusion gene for microinjection. Restriction sites shown are: (B) BamHI; (Bg) BgIII; (E) EcoRI; (H) HindIII; (N) NcoI; (P) PstI; (S) SalI; (Sp) SphI. (b) CAT enzyme protein and CAT DNA accumulations in $L$. variegatus embryos developing from injected eggs. Each fertilized egg received about 1500 linearized CyIIIa - CAT DNA molecules. At $5 \mathrm{hr}$ postfertilization 400 embryos were pooled and lysed for CAT enzyme determination, and 40 embryos were similarly pooled and lysed at $10 \mathrm{hr}$ and $24 \mathrm{hr}$. In this experiment a level of $1.3 \times 10^{5} \mathrm{CAT}$ enzyme molecules per average embryo would have given $2 \times$ background activity in the CAT assays utilized (see Materials and methods), and this is taken as the minimum level that would have been detectable. Though no CAT activity above background was actually observed in the 5 -hr sample, the nominal maximum value of this point that might have escaped detection is plotted (in parentheses), i.e., $1.3 \times 10^{5}$ molecules/embryo (see text). An additional aliquot of 100 embryos at each time point was used for measurement $(\mathbf{\Delta})$ by filter hybridization (see Materials and methods) of the average number of CyIIIa CAT DNA genes per embryo.

some manner with nuclear components that potentiate efficient replication. Thus, during the later half of cleavage the average relative rate of exogenous DNA replication in a given batch of embryos (i.e., including those embryos in which the exogenous DNA was never successfully incorporated into the nuclear compartment at all, or was not actually delivered) lies within a factor of two of the overall relative rate of cellular DNA replication. An experiment in which CAT enzyme protein accumulation and DNA amplification were measured at cleavage ( $5 \mathrm{hr}$ ), blastula ( $10 \mathrm{hr}$ ), and gastrula ( $24 \mathrm{hr}$ ) in the same batch of injected $L$. variegatus eggs is shown in Figure $1 b$, and CAT enzyme accumulation data for seven additional experiments are listed in Table 1. The DNA replication kinetics shown in Figure $1 \mathrm{~b}$ fall within the range observed earlier (Franks et al. 1987). Thus, by $24 \mathrm{hr}$ there has occurred a total average increase of $\sim 30$-fold, following an early lag, and the average replication between 5 and $10 \mathrm{hr}$ postfertilization is 3.6 -fold. The cellular genomes increase about fivefold during the equivalent interval, i.e., from 4 to $9 \mathrm{hr}$ (taking into account the $\leq 1$-hr delay in initiation of cleavage). CAT enzyme measurements are expressed here as average number of CAT enzyme protein molecules per embryo, on the basis of earlier calibrations (see Materials and methods, and McMahon et al. 1984). In the experiment shown in 
Table 1. CAT enzyme molecules per embryo in embryos of cytoplasmic and nuclear injection series

\begin{tabular}{rllllllll}
\hline Experiment & & 1 & 2 & 3 & 4 & 5 & 6 & 7 \\
\hline $10-11 \mathrm{hr}$ & $\mathrm{N}$ & $6.4 \times 10^{6}$ & $7.8 \times 10^{6}$ & $7.8 \times 10^{6}$ & $1.0 \times 10^{7}$ & $4.4 \times 10^{7}$ & $1.6 \times 10^{7}$ & $4.2 \times 10^{7}$ \\
& $\mathrm{C}$ & $1.1 \times 10^{7}$ & $5.3 \times 10^{6}$ & $5.3 \times 10^{6}$ & $9.7 \times 10^{6}$ & $1.3 \times 10^{7}$ & $2.2 \times 10^{7}$ & $1.6 \times 10^{7}$ \\
& $\mathrm{~N} / \mathrm{C}$ & 0.58 & 1.47 & 1.47 & 1.03 & 3.38 & 0.73 & 2.63 \\
$20-24 \mathrm{hr}$ & $\mathrm{N}$ & $2.0 \times 10^{7}$ & $1.3 \times 10^{7}$ & $1.1 \times 10^{7}$ & $5.2 \times 10^{7}$ & $9.2 \times 10^{7}$ & $1.6 \times 10^{7}$ & $6.5 \times 10^{7}$ \\
& $\mathrm{C}$ & $7.9 \times 10^{6}$ & $1.1 \times 10^{7}$ & $1.3 \times 10^{7}$ & $2.6 \times 10^{7}$ & $7.2 \times 10^{7}$ & $1.9 \times 10^{7}$ & $9.7 \times 10^{7}$ \\
& $\mathrm{~N} / \mathrm{C}$ & 2.53 & 1.18 & 0.85 & 2.00 & 1.28 & 0.84 & 0.67 \\
$48 \mathrm{hr}$ & $\mathrm{N}$ & $2.0 \times 10^{7}$ & $1.1 \times 10^{7}$ & $5.3 \times 10^{6}$ & $1.8 \times 10^{7}$ & $3.6 \times 10^{7}$ & $3.1 \times 10^{6}$ & $4.8 \times 10^{7}$ \\
& $\mathrm{C}$ & $4.8 \times 10^{6}$ & $1.1 \times 10^{7}$ & $5.2 \times 10^{5}$ & $1.6 \times 10^{6}$ & $2.0 \times 10^{7}$ & $3.1 \times 10^{6}$ & $2.5 \times 10^{7}$ \\
& $\mathrm{~N} / \mathrm{C}$ & 4.17 & 1.00 & 10.19 & 11.25 & 1.80 & 1.00 & 1.92 \\
\hline
\end{tabular}

Embryos derived from cytoplasmic $(\mathrm{C})$ and nuclear $(\mathrm{N})$ injection of zygotes were collected at the indicated times and assayed for CAT enzyme activity. In each experiment a single batch of eggs was used for both cytoplasmic and nuclear injection. Each egg was injected with either $3 \times 10^{3}$ (experiments 1-3) or $7 \times 10^{3}$ (experiments 4-7) CyIIIa CAT DNA molecules. At each time point 25-40 embryos were pooled, and the average number of CAT enzyme molecules per embryo was determined.

${ }^{a}$ Ratio: Average number of CAT enzyme molecules per embryo derived from nuclear injection/average number of CAT enzyme molecules per embryo derived from cytoplasmic injection.

Figure $1 \mathrm{~b}$, no CAT enzyme could be detected in 5-hr embryos, which are in the 5 th-6th cleavage cycle, nor could CAT activity be detected at $5 \mathrm{hr}$ in any of the seven experiments shown in Table 1. The limit of detection, which depends on the number of embryos per sample as well as the specific activity of the $\left[{ }^{14} \mathrm{C}\right]$ chloramphenicol used and other assay parameters, differs for each experiment. The experiment of Figure 1 provides the most critical evidence, as 400 embryos were utilized for the 5-hr time point, compared with $25-40$ in the experiments of Table 1 . An average CAT enzyme content of about $10^{5}$ molecules per embryo would have been detectable in this experiment (see Fig. 1 legend), and Figure $1 \mathrm{~b}$ shows that between 5 and $10 \mathrm{hr}$ postfertilization CAT enzyme accumulated from a level below $10^{5}$ to an average value of over $3 \times 10^{6}$ molecules per embryo.

In $S$. purpuratus embryos developing from eggs injected with CyIIIa - CAT a similar sharp increase in CAT enzyme protein levels occurs between $10 \mathrm{hr}$, when the enzyme is undetectable, and $15 \mathrm{hr}$ postfertilization (Flytzanis et al. 1987). The conclusion was drawn for that case that the ontogenic appearance of CAT enzyme results from activation of productive CAT gene transcription, i.e., from a sharp increase after $10 \mathrm{hr}$ in rate of synthesis of CAT mRNA per CyIIIa - CAT gene present. Thus, although our measurements demonstrated sufficient CyIIIa-CAT DNA to be present in the $S$. purpuratus embryo nuclei at $10 \mathrm{hr}$ to support the synthesis of the maximum levels of CAT enzyme found later, no detectable CAT enzyme is ever produced in 10-hr transgenic embryos (Flytzanis et al. 1987). Furthermore, when the same CAT reporter gene was placed under the control of $\alpha \mathrm{H} 2 \mathrm{~A}$ histone regulatory sequences, and this fusion injected into $S$. purpuratus eggs, CAT enzyme synthesis was activated several hours earlier, i.e., at the stage when the endogenous $\alpha \mathrm{H} 2 \mathrm{~A}$ histone genes are normally transcribed at maximal rates. While to our knowledge an experiment has not been carried out with $L$. variegatus eggs injected with $\alpha$-histone genes, a recent study of Colin et al. (1987) shows that exogenous $S$. purpuratus $\alpha$-histone genes are activated appropriately during cleavage in L. pictus embryos raised from cytoplasmically injected eggs. These observations demonstrate that midcleavage sea urchin eggs are indeed capable of expressing those exogenous genes that are normally expressed at that stage, and thus that the quiescence of the CyIIIa.CAT construct during cleavage in the transgenic $L$. variegatus embryos is probably sequence specific. Figure 1 also provides a quantitative argument that specifically requires a significant increase in the rate of production of CAT enzyme per CAT gene in these embryos between 5 and $10 \mathrm{hr}$ postfertilization. Here it is important to keep in mind that CAT enzyme protein and mRNA are unstable in sea urchin embryos. The half-life estimated for the protein in S. purpuratus embryos is about $40 \mathrm{~min}$ (Flytzanis et al. 1987). Though there is no direct evidence, we assume this turnover rate for the present case. The steady-state synthesis rate for the number of CyIIIa CAT genes present at 10 hr (i.e., $9 \times 10^{3}$ genes/embryo; Fig. 1 b) would then be about 370 enzyme molecules produced per gene $\cdot \mathrm{hr}^{1}$. At $5 \mathrm{hr}$ there are already about $2.5 \times 10^{3}$ CyIIIa CAT genes/embryo, though no more than $1 / 30$ as much CAT enzyme protein as at $10 \mathrm{hr}$. Were CAT enzyme synthesis at $5 \mathrm{hr}$ in fact occurring at the same rate as at $10 \mathrm{hr}$ (i.e., no gene activation between 5 and $10 \mathrm{hr}$ ), there should have been present at least $8.9 \times 10^{5}$ molecules of CAT enzyme/embryo, on the average, ${ }^{1}$ i.e., about $7 \mathrm{X}$ the conservative nominal limit of detection. Thus, as previously

\footnotetext{
${ }^{1}$ This calculation may be made as follows, assuming the 40 -min half-life $\left(t_{1 / 2}\right)$ for CAT enzyme (Flytzanis et al. 1987): let $k_{s}$ be the synthesis rate (molecules/hr - embryo); $k_{d}$ the turnover rate, i.e. $\ln 2 / t_{1 / 2}\left(\mathrm{hr}^{-1}\right) ; C$, the steady state CAT content (molecules/embryo); $G$, the number of CyIIIa - CAT genes (molecules/embryo). For the synthesis rate per gene, $k_{s} / G=C \cdot \ln 2 / t_{1 / 2} \cdot G$. For the period around $10 \mathrm{hr}, G$ is $9 \times 10^{3}$; $C$ is $3.2 \times 10^{6}$; if $t_{1 / 2}=0.67 \mathrm{hr}, k_{s} / G=367$ molecules $/ \mathrm{hr} \cdot$ gene. If the synthesis rate per gene were to be the same at $5 \mathrm{hr}$, when $G=2.5 \times 10^{3}$, then $C$ would be given by $(367)(0.67)\left(2.5 \times 10^{3}\right) / \ln 2$ or $8.9 \times 10^{5}$ molecules/embryo, $\sim 6.8 \times$ the nominal limit of detection.
} 
reported for $S$. purpuratus, the CyIIIa $\cdot$ CAT gene appears to be ontogenically activated in the transgenic $L$. variegatus embryos.

The embryonic stage when this apparent activation occurs is just as would be predicted, were the CyIlla regulatory sequences of the construct interacting with factors that are normally bound by homologous regulatory sequences of the $L$. variegatus equivalent of the CyIIIa actin gene (or perhaps of other genes of an $L$. variegatus aboral ectoderm gene battery). That is, the construct is expressed when $L$. variegatus embryos should initially activate their own aboral ectoderm-specific genes, assuming the same relative developmental timing as in $S$. purpuratus. Furthermore, the quantitative levels of CAT enzyme produced in the different batches of transgenic embryos (Table 1) fall within that range normally observed in $S$. purpuratus embryos raised from eggs cytoplasmically injected with CyIIIa $\cdot$ CAT (Flytzanis et al. 1987; Katula et al. 1987). Though CAT turnover rate has not been measured directly for $L$. variegatus embyros, it may be noted that overall transcription, translation, and mRNA turnover rates are about the same in L. pictus as in S. purpuratus (reviewed by Davidson 1976, 1986).

\section{Expression of CyIIIa $\cdot$ CAT gene injected into $\mathrm{L}$. variegatus zygote nucleus or cytoplasm}

Experiments were carried out to determine whether the same kinetics of CAT enzyme accumulation would be observed if the CyIIIa - CAT was injected directly into the $L$. variegatus zygote nucleus. Franks et al. (1987) found that in both cytoplasmic and nuclear $L$. variegatus injection samples, the mass of exogenous DNA amplified about 10- to 40 -fold by the end of embryogenesis, but they concluded from an analysis of transgenic larvae and juveniles that nuclear injection often results in earlier stable association with nuclear elements during cleavage. Thus, it was important to discover whether differences in embryonic CAT enzyme expression might be detected that would depend systematically on the route of CyIIIa - CAT introduction. A series of seven experiments was performed in which matched samples drawn from given batches of eggs were injected in either nucleus or cytoplasm, and CAT enzyme content was estimated at $5 \mathrm{hr}, 10-11 \mathrm{hr}, 20-24 \mathrm{hr}$, and $48 \mathrm{hr}$ (late pluteus stage). CAT assays for a typical experiment are shown in Figure 2, and in Table 1 the average CAT enzyme contents of embryos of the nuclear injection series at these time points are compared to those of their cytoplasmic injection controls, which were considered above. In none of the seven experiments shown could CAT enzyme be detected in the 5-hr sample, while in all of the experiments CAT enzyme had appeared by $10 \mathrm{hr}$, just as already described for cytoplasmically injected eggs.

As shown by the N/C ratios in Table 1 , the amounts of CAT enzyme produced at $10-11 \mathrm{hr}$ and $20-24 \mathrm{hr}$ postfertilization were not significantly greater, on the average, in the nuclear than in the cytoplasmic injection

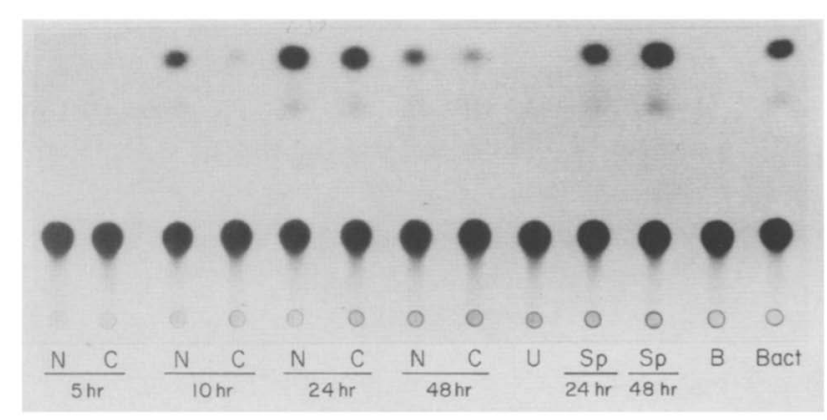

Figure 2. CAT enzyme assays illustrating temporal course of CyIIIa - CAT expression, and comparison of nuclear and cytoplasmic injection samples. (N) nuclear; (C) cytoplasmic injection sample; $\sim 7000$ molecules of CyIIIa $\cdot$ CAT injected per egg. Each assay was carried out on 25 embryos, and all embryos utilized for the experiment shown were from a single batch of eggs. L. variegatus embryos $\left(23^{\circ} \mathrm{C}\right)$ at $5 \mathrm{hr}$ are in cleavage; at 12 $\mathrm{hr}$, early blastula; at $24 \mathrm{hr}$, late gastrula; at $48 \mathrm{hr}$, late pluteus stage. (U) Assay of lysate from 25 uninjected embryos; (Sp) $S$. purpuratus embryos serving as controls for this species (at $\left.16^{\circ} \mathrm{C}\right) .(24 \mathrm{hr}$ ) Hatching blastula; (48 hr) early pluteus stage. (B) Blank lane; (Bact) bacterial CAT enzyme standard.

samples (Table 1). In both, the CAT content tended to increase about twofold between $10-11$ and 20-24 hr. Thus, the averages of the ratios $\mathrm{N}_{20-24} / \mathrm{N}_{10-11}$ and $\mathrm{C}_{20-24} / \mathrm{C}_{10-11}$ are 2.3 and 2.9 , respectively, though as illustrated in Figure $1 \mathrm{~b}$, this is not invariably observed. By $48 \mathrm{hr}$, however, embryos of the nuclear injection series displayed about $5 \times$ more CAT enzyme, on the average, than did the embryos of their cytoplasmic injection controls (a one-tailed $t$ test, which for this case is a very conservative index, suggests that this difference is significant at the 0.025-0.05 level). Inspection of Table 1 shows that between $20-24$ and $48 \mathrm{hr}$ both the nuclear and cytoplasmic injection samples lost active CAT enzyme, but that in some experiments [e.g., experiments 3 , 4, and 5 (see Fig. 2)] the loss in the cytoplasmic injection samples was much greater. We believe it unlikely that this phenomenon relates to preferential loss of exogenous DNA in the cytoplasmic injection samples, because Franks et al. (1987) detected no difference in exogenous DNA retention dependent on route of introduction. Thus, for example, their measurements indicate almost equal CAT DNA contents at $48 \mathrm{hr}$ in samples of the same nuclear and cytoplasmic injection series as were used for experiment 7 of Table 1 in this paper, while on the other hand, Table 1 indicates an approximately threefold greater decline in CAT enzyme between 24 and $48 \mathrm{hr}$ in the cytoplasmic injection sample of experiment 7 . That is, the loss of CAT enzyme activity is in this case clearly not the consequence of preferential DNA loss. If $L$. variegatus utilizes a CyIlla-like actin gene, the developmental controls of which are homologous with those of the $S$. purpuratus CyIIIa gene, an explanation for the loss of CAT enzyme content late in development in the present experiments might lie in a decreased rate of synthesis, combined with the instability of CAT protein and mRNA. Thus, there is evi- 
dence for $S$. purpuratus that CyIIIa transcription rate per nucleus is itself turned down in advanced embryos (Lee 1986; Lee et al. 1986). The more moderate decrease in the nuclear injection samples in the present study could be due to the increased likelihood that the CyIIIa - CAT fusion will be included in cells that are undergoing replication during the pluteus stage of development (Franks et al. 1987).

These experiments demonstrate that the quantitative kinetics of CyIIIa - CAT activation in transgenic $L$. variegatus embryos remain essentially the same, i.e., between 5 and $24 \mathrm{hr}$, irrespective of the route by which the exogenous DNA is introduced into the zygote. This result excludes the alternative that the apparent lack of CAT activity during cleavage in the cytoplasmic injection experiments considered above could be due to a delay of several hours in incorporation of the exogenous DNA into the nuclear compartments, where transcription may occur, rather than to ontogenic gene activation.

\section{Ubiquitous spatial expression of CyIIIa $\cdot$ CAT in transgenic L. variegatus embryos}

Current unpublished studies from this laboratory show that expression of the $S$. purpuratus CyIIIa gene is controlled by multiple DNA-protein interactions occurring within the cis regulatory domain included in the CyIIIa-CAT construct. Some of these interactions might be sufficient to mediate temporal activation, while others could be required for spatial control. Therefore, we examined the transgenic $L$. variegatus embryos by in situ hybridization, using an antisense CAT probe. Although in transgenic $S$. purpuratus embryos bearing the CyIIIa CAT construct only aboral ectoderm cells express the CAT gene (Hough-Evans et al. 1987), the CyIIIa - CAT DNA is present in some cells of all types, due to the random mosaic incorporation (B. HoughEvans, R. Britten, and E. Davidson, in prep.). To provide a standard of comparison and controls for the present experiments, further observations were made on $S$. purpuratus embryos raised from eggs that had received cytoplasmic injections of CyIIIa - CAT. CAT mRNA was again found to be confined strictly to cells of the aboral ectoderm, and no labeling was ever observed in skeletogenic or secondary mesenchyme cells, or cells of the vegetal plate or archenteron. These results are illustrated in Figure 3.

We analyzed in situ CAT hybridizations carried out on over 50 different $L$. variegatus embryos derived from two different cytoplasmic injection series. For the large majority of these embryos, complete sets of serial sections were recovered. As summarized in Table 2, most of the embryos displayed easily detectable CAT mRNA accumulations in mesenchyme cells as well as ectoderm cells, and about half displayed these in gut cells as well. Furthermore, the transgenic $L$. variegatus embryos synthesized CAT mRNA in oral as well as aboral ectoderm. Some typical sections illustrating these unexpected
CAT mRNA localizations are shown in Figure 4. Figure 4 a-c displays $L$. variegatus embryos in which gut, ectoderm, and mesenchyme cells all reveal easily detectable accumulations of CAT mRNA. As expected, the pattern of expression, reflecting the pattern of exogenous DNA incorporation, is mosaic (Flytzanis et al. 1985, 1987; Franks et al. 1987; Hough-Evans et al. 1987), though to different extents in the different embryos. Thus, a relatively small number of cells in the embryos of Figure 4,a and $b$ are labeled compared with the more extensive labeling in Figure 4d. Oral ectoderm as well as aboral ectoderm labeling can be seen in Figure 4,b and d. Figure 4c shows two embryos in which labeling is primarily, though not exclusively, confined to skeletogenic mesenchyme cells. As can be seen in Table 2, labeling of mesenchyme cells is observed commonly in the sample studied, perhaps reflecting a minor bias, either with respect to exogenous DNA incorporation or expression, in favor of this cell type.

The striking ubiquity, with respect to cell type, in CAT mRNA localization displayed in Figure 4, and the high reproducibility of this result (Table 2) leave little doubt that the regulatory interactions directing CyIIIa expression to the aboral ectoderm in $S$. purpuratus fail to operate when the CyIIIa regulatory domain is introduced into $L$. variegatus. We have never observed a transgenic embryo of the latter species in which the CAT mRNA was actually confined to aboral ectoderm, nor is there clear evidence for any cell type in these embryos from which CAT mRNA was always excluded. Whatever the explanation, since temporal expression is apparently maintained, these results imply that the cis-trans interactions responsible for spatial and temporal regulation are separable.

\section{Discussion}

We report here that regulatory sequences of the $S$. purpuratus CyIIIa actin gene appear to mediate a much less specific, or more probably a ubiquitous, spatial pattern of gene expression during development when introduced into $L$. variegatus eggs, as compared with the aboral ectoderm-specific pattern observed when the same fusion gene construct is introduced into eggs of the species from which the gene derives. Yet temporal activation of expression occurs at the appropriate developmental stage in the transgenic $L$. variegatus embryos. Thus, at least a portion of the regulatory interactions responsible for the control of the $S$. purpuratus CyIIIa actin gene functions when the gene is present in the nuclei of $L$. variegatus embryos. It may be relevant that Crain and Bushman (1983) found that the CyI and the CyIIIa actin genes of $S$. purpuratus are expressed in $S$. purpuratus $\delta / L$. variegatus $q$ species hybrids. In any case the observations reported here that the exogenous CyIIIa fusion gene is activated at the blastula stage of the host embryos, together with the arguments given in Results based on assay sensitivity and quantity of CAT enzyme produced, eliminate the trivial possibility that the CyIIIa - CAT fusion is being expressed constitutively in 


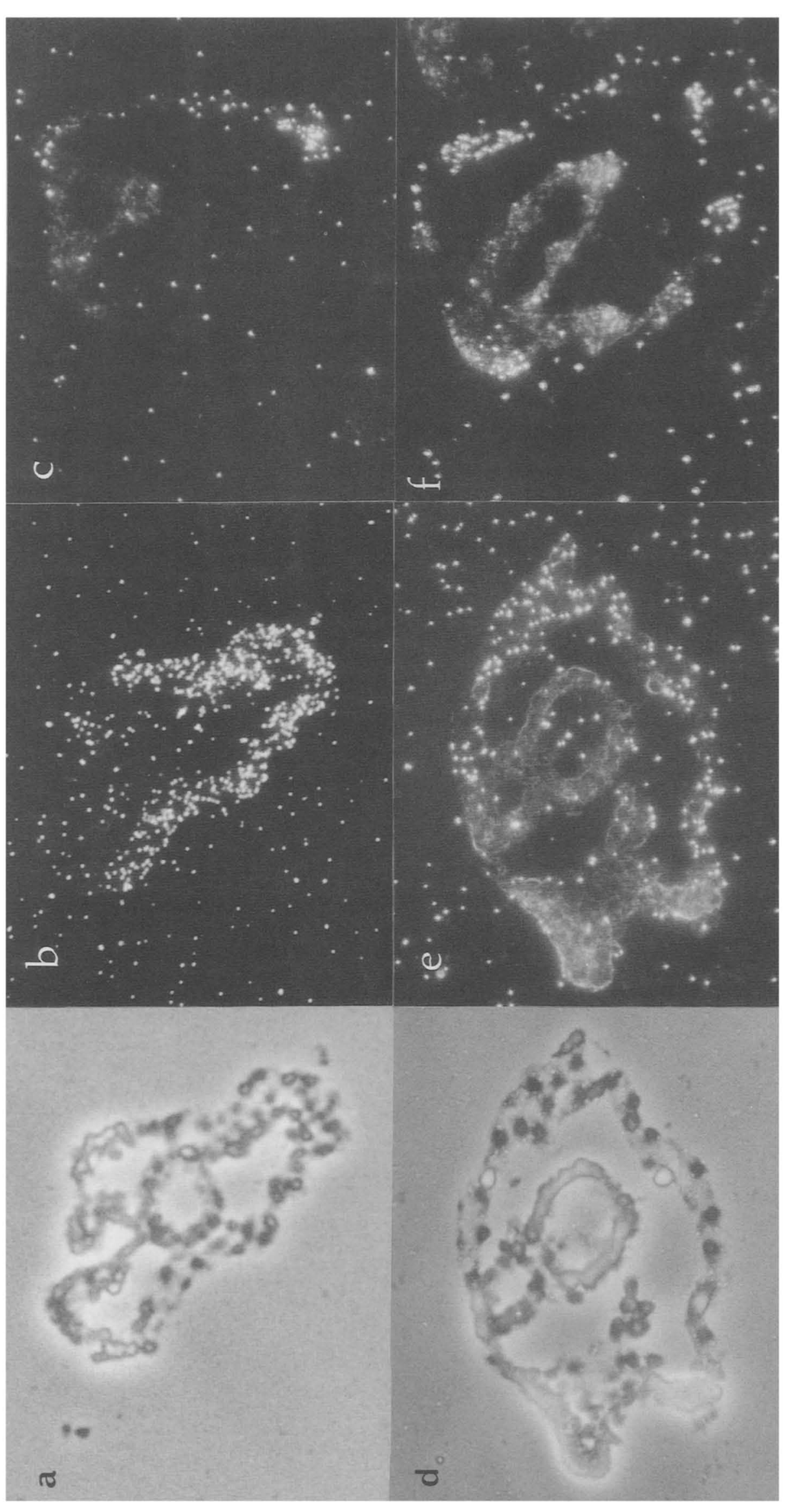

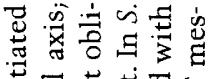

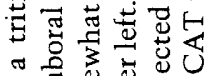
击 उ $\frac{1}{3} 0_{0}$

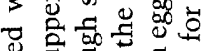

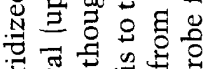

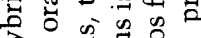

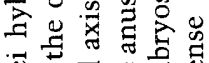
Ф तु

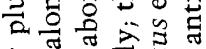

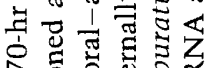

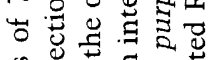
की

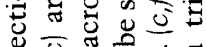

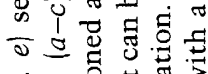
ช. .9. ○

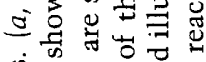

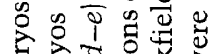

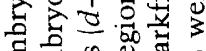

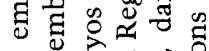

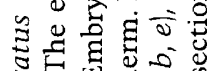
파

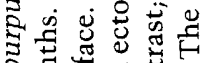
ฉ若苛吉

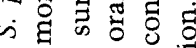

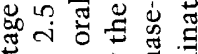
क

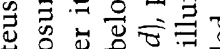

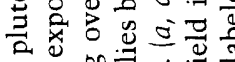
ठै

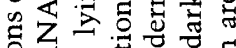

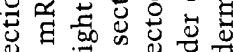
क $\Xi$ ज

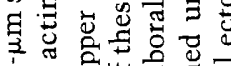

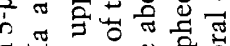

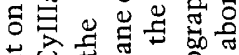

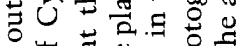

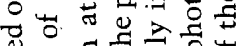
范吉出

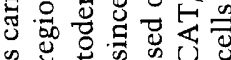
अ

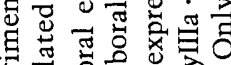

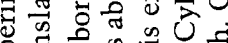

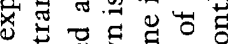

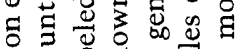

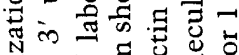

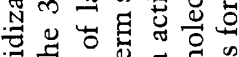
편요 영

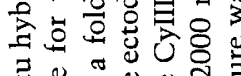
考 。 $\Xi$ 重苍焉 m

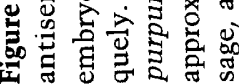


Table 2. CAT mRNA accumulations visible by in situ hybridization in pluteus stage $\mathrm{L}$. variegatus embryos raised from eggs injected with CyIIIa $\cdot$ CAT $^{\mathrm{a}}$

\begin{tabular}{lcccrc}
\hline & $\begin{array}{c}\text { Embryos } \\
\text { analyzed }\end{array}$ & $\begin{array}{c}\text { Embryos } \\
\text { labeled }\end{array}$ & \multicolumn{3}{c}{ Location of labeled cells } \\
\cline { 4 - 6 } & mesenchyme $^{\mathrm{d}}$ & gut & ectoderm $^{\mathrm{e}}$ \\
\hline Complete $^{\mathrm{b}}$ & 48 & 46 & 45 & 24 & 42 \\
Partial $^{\mathrm{b}}$ & 6 & 6 & 6 & 1 & 3
\end{tabular}

a Observations on 24-hr embryos.

b Complete, all serial sections recovered; partial, at least one section recovered.

${ }^{c}$ Embryos distinctly labeled with antisense CAT mRNA probe in at least one section.

d Including both skeletogenic and secondary mesenchyme.

e Including both oral and aboral ectoderm, which in some orientations are difficult to demarcate.

a wholly nonregulated manner as, for example, might be the case if transcription were occurring from a cryptic vector promoter. It is most unlikely that such an explanation would obtain for the transgenic $L$. variegatus embryos in any case, as use of vector promoters was clearly excluded for transgenic $S$. purpuratus promoters by the deletion experiments of Flytzanis et al. (1987). Several possible alternative interpretations are considered.

1. A negative spatial control model. A consistent interpretation of these results can be constructed on the basis that the normal regulatory system controlling CyIIIa gene expression (i.e., in S. purpuratus), depends on both positive and negative cis-trans interactions. Our current evidence indicates that temporal activation of the gene at the early blastula stage must be controlled positively. If the amount of CyIIIa - CAT DNA injected per egg is increased, the amount stably incorporated and replicated during embryogenesis increases, and the amount of CAT enzyme synthesized also increases, until a plateau is attained. The quantitative effects on CAT enzyme production of both subsaturating and excess exogenous DNA conditions require the assumption of positive regulation. Thus, in the subsaturating range of CyIIIa - CAT DNA content, the CAT enzyme synthesis per incorporated gene remains constant as the number of genes is increased from very low numbers of injected genes (D. Livant, R. Britten, and E. Davidson, in prep.). When sufficient CyIIIa - CAT DNA is present to produce the plateau values of CAT enzyme, however, the CyIIIa regulatory sequences compete with one another, and the amount of CAT enzyme produced per incorporated CAT gene declines, as the number of genes increases (Flytzanis et al. 1987; D. Livant et al., in prep.). Furthermore, as implied by the latter result, in vivo competition experiments can be carried out in which excess regulatory DNA sequence is coinjected with the CyIIIa - CAT DNA. All sequences thus far tested cause decrease of CAT enzyme activity rather than increase, sometimes proportionately to the molar ratio of competing regulatory sequence to CyIIIa $\cdot \mathrm{CAT}$ injected $(\mathrm{R}$. Franks, D. Livant, and E. Davidson, unpubl.). These results all require positive rather than negative regulatory interactions, with the available positively acting trans factors present at concentrations that can be titrated out by injecting relatively large numbers of CyIIIa $\cdot$ CAT genes or large quantities of CyIIIa regulatory sequence. However, no evidence excludes the possibility that among the eight protein binding sites we have discovered in the CyIIIa regulatory domain (F. Calzone et al., in prep.l, one or more could be utilized for repression of CyIIIa transcription in oral ectoderm, skeletogenic mesenchyme, and vegetal plate derivatives, while activation is mediated by embryo-wide factors that bind to other regulatory sequence elements. That is, the genes would be silent early in development, pending the developmental presentation of the activating factors, and would thereupon be expressed, but only in those cells that lack the repressive spatial control factors, that is, the cells of the aboral ectoderm. The ectopic expression of CyIIIa CAT shown in Figure 4 of this paper could thus be interpreted as the consequence of evolutionary divergence in the genes coding for the spatial repression factor(s) or the cis-acting sequences. The correct temporal activation of CyIIIa. CAT in transgenic $L$. variegatus embryos implies sufficient conservation for recognition of the positive control factors, which would be homologous in both structure and function with those mediating CyIIIa activation in S. purpuratus. Note in this connection that the amounts of CAT enzyme accumulation in the transgenic $L$. variegatus embryos is about the same as in $S$. purpuratus embryos bearing CyIIIa $\cdot$ CAT. Were the putative repressive interactions controlling spatial expression to fail, however, CAT mRNA would accumulate in all cell types, as observed.

Among the directly testable consequences of this model is that coinjection of competing quantities of the negative cis-regulatory site(s) into $S$. purpuratus eggs with CyIIIa - CAT should generate in situ CAT mRNA hybridization patterns similar to those observed in Figure 4 of this paper. Furthermore, in vivo footprints carried out on embryo fractions (e.g., gut versus ectoderm) would reveal that certain of the eight cis-regulatory sequences are bound in cells not expressing the CyIIIa gene, rather than vice versa. We note here that the protein extracts so far utilized for in vitro DNA binding studies have all been obtained from whole embryo nuclei, and we do not yet know whether any of them are sequestered to certain cell lineages.

2. Positive spatial regulation. Can the derangement of CyIIIa spatial regulation observed in $L$. variegatus be rationalized if normal expression in S. purpuratus is mediated by interactions that function positively rather than negatively? We suppose here that the CyIIIa gene is activated by a cooperative or additive mechanism in which binding of both temporal and spatial positive factors is required. That is, the necessary temporal factors could (though they need not) be embryo-wide in spatial distribution, but the gene would be functional only in aboral ectoderm cells because in these the additional spatial factor(s) (which need not be temporally regulated) are available or activated. In this case, in con- 


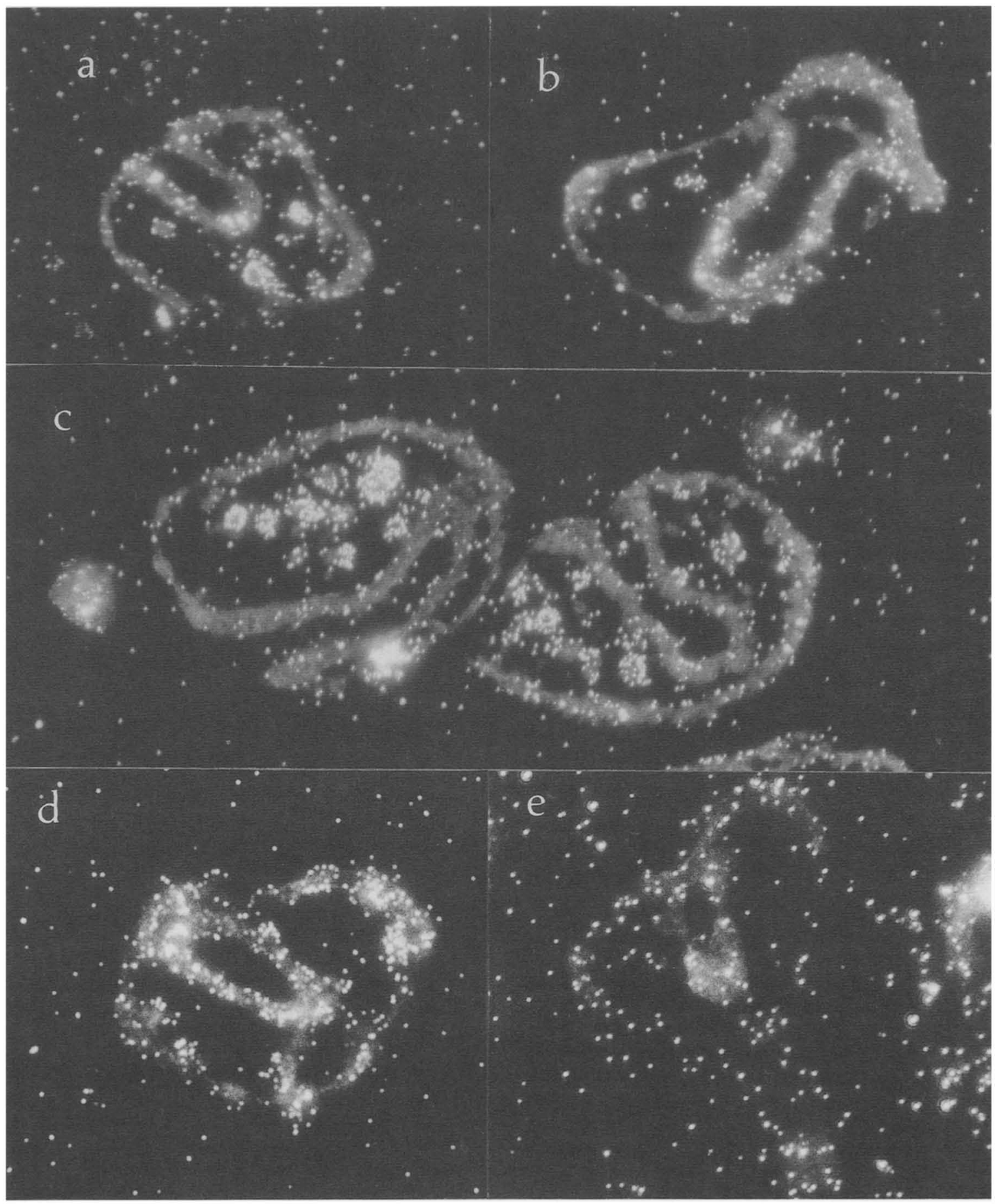

Figure 4. In situ hybridizations of 24-hr Lytechinus variegatus plutei from two different series of injections. (a-d) Pluteus-stage embryos from eggs injected with CyIIIa CAT. Hybridization conditions were the same as for the $S$. purpuratus CAT hybridizations shown in Figure $3(c, f)$. (a) Labeling in cells of ectoderm, gut, and primary mesenchyme. The anus is at the upper left in this section, and all of the ectoderm shown is aboral ectoderm. The plane of the section is similar to that of Figure $3 \mathrm{~d}$. $(b) \mathrm{A}$ few cells of ectoderm, gut, and primary mesenchyme labeled in a second pluteus. In the gut the esophagus is to the lower part of the embryo (orientation was determined by examining serial sections). Note that some of the cells of the oral ectoderm adjacent to the esophagus are labeled, as well as aboral ectoderm cells elsewhere. (c) Sections of two plutei labeled primarily in mesenchyme cells. In each embryo the section passes through the anus. (d) Heavily labeled embryo, second injection series. The gut is sectioned through the esophagus and stomach, and labeled oral ectoderm appears at the upper left. (e) Control $L$. variegatus pluteus (developed from an egg that was not injected) from the same slide as the section in $d$. Sections of control embryos were included on each slide and carried through the entire in situ hybridization procedure along with sections of experimental samples. No cells are labeled. The bright background glow over parts of the tissue in $d$ and $e$ is an artifact of the darkfield illumination. 
trast to that considered above, in vivo competition experiments in which excess quantities of cis-regulatory sequence are coinjected into $S$. purpuratus eggs with CyIIIa - CAT would never be expected to alter the spatial distribution of CAT transcripts, except for depression of their level of accumulation. Evolutionary divergence might plausibly result in derangement of a positive spatial control system as well, with results such as observed in Figure 4 of this paper. Thus, for example, a sequence that in $S$. purpuratus requires some form of cooperative interaction with a spatially presented trans activator might behave independently as an overriding positive control element when bound by the "evolutionarily mutated" L. variegatus protein $(\mathrm{s})$.

\section{Evolutionary alteration of developmental identity} among the cytoskeletal actins. As pointed out above, we do not yet know if $L$. variegatus utilizes an aboral ectoderm-specific cytoskeletal actin, though it may indeed utilize an aboral ectoderm-specific gene battery, since its congener, L. pictus, generates localized Spec proteins (see introductory section). The five functional cytoskeletal actin genes of $S$. purpuratus code for proteins that differ by only a few percent at most in amino acid composition (cf. Akhurst et al. 1987). Their codogenic similarity contrasts with their sharply diverse patterns of developmental utilization (Shott et al. 1984; Cox et al. 1986). This comparison leads to the view that the members of this gene family can be considered as essentially interchangeable replicates at the proteincoding level, each of which participates in a separate regulatory network, or gene battery, controlled by lat least somel cis-trans interactions not shared with other differentially expressed actin genes. The evolutionary process by which genes are duplicated and inserted into cell-type- or cell-lineage-specific gene batteries might be among the most important in accounting for the phylogenetic appearance of novel structures in organismal evolution (Britten and Davidson 1971; Davidson 1982). We may have stumbled upon a case in which we can see two different regulatory gene assignments normally mediated in the two species by the same cis sequence information. That is, we could assume that the results shown in Figure 4 represent the normal spatial pattern of expression of an $L$. variegatus gene utilizing the CyIIIa cisregulatory sequences. In contrast to the two cases considered above we could argue that evolutionary divergence has not resulted in failure of appropriate interactions to occur. However, during evolution the distribution of the relevant trans factors among cell lineages early in development would have become dissimilar in these two echinoid branches (the cell lineages themselves are probably very similar; Davidson 1986). The consequence would be a different spatial pattern of utilization of the same gene in the two species, e.g., the generation of a pattern of Cyllla actin gene expression that resembles that of CyI, a different, unlinked cytoskeletal actin gene in $S$. purpuratus, which is expressed in many different cell lineages. Since the actins contribute directly to cell-type-specific shape, form, and function, here might be a most interesting example of developmental regulatory evolution.

We are at present examining the cytoskeletal actin genes of $L$. variegatus to determine whether there is an aboral ectoderm-specific member of this family. CyIIIa has a special diagnostic internal feature, despite its overall codogenic similarity to the other cytoskeletal actins, namely, an 11-amino-acid sequence that includes five unique changes with respect to other known actins (amino acids 256-266; Akhurst et al. 1987). This feature, and the patterns of gene expression, should allow us to determine whether a different aboral-ectodermspecific cytoskeletal actin gene is indeed utilized in $L$. variegatus, and how the CyIIIa-like gene, if it exists, is utilized. Whatever the outcome, these considerations may provide an example of the conceptual convergence, within the domain of gene regulation, of evolutionary and developmental mechanisms.

\section{Materials and methods}

\section{Injection of DNA into L. variegatus eggs}

The procedure utilized is essentially that of McMahon et al. (1985), as modified by Franks et al. (1987). The latter authors described in detail methods for injection of DNA into either nucleus or cytoplasm of zygotes of this species. Briefly, the eggs are dejellied by a short exposure to $\mathrm{pH} 4.8$ seawater, fixed electrostatically to protamine sulfate-coated dishes, fertilized, and, following pronuclear fusion (about $20 \mathrm{~min}$ postfertilization), injected with a continuously flowing microneedle. For the present studies CyIIIa - CAT was linearized at the unique Sph1 site (Fig. 1), and about $2 \mathrm{pl}$ of a $40 \%$ glycerol solution containing approximately $1500-7000$ molecules as indicated, were delivered, on the average, to each egg. Eggs injected in the nucleus received an unknown fraction of the DNA solution in the cytoplasm as well, but as shown by Franks et al. (1987) the results of nuclear injection can be clearly distinguished from those of exclusively cytoplasmic injection. On the average $60-65 \%$ of embryos in nuclear injection samples and $75-80 \%$ of embryos in cytoplasmic injection samples developed normally to form pluteus larvae able to begin feeding. For $L$. variegatus embryos grown at $23^{\circ} \mathrm{C}$ this stage is attained about $48 \mathrm{hr}$ postfertilization. Injected embryos often lagged behind uninjected controls by about $1 \mathrm{hr}$, due to a pause of this length prior to the initiation of cleavage.

\section{Assay of CAT enzyme content and CAT DNA content in} embryos bearing exogenous DNA

CAT activity was measured by a procedure similar to that described earlier (McMahon et al. 1984; Flytzanis et al. 1987). Centrifugal pellets containing 25-50 injected embryos were lysed by three consecutive freeze-thaw cycles in $50 \mu \mathrm{l} 250 \mathrm{mM}$ Tris- $\mathrm{HCl}(\mathrm{pH} 7.8)$. CAT activity in the lysates was assayed according to Gorman et al. (1982) and McMahon et al. (1984). Various concentrations of bacterial CAT enzyme (P-L Biochemicals, Milwaukee, Wisconsin) were assayed in parallel as standards. The fractions of the substrate $\left[\left({ }^{14} \mathrm{C}\right]\right.$ chloramphenicol $)$ converted in each sample to acetylated derivatives were used for calculation of the accumulated number of CAT enzyme molecules. We assumed for these measurements the equivalence determined for the same assay conditions of McMahon et al. (1984), using as standard a largely pure sample of CAT enzyme protein of recombinant origin, namely, 1 unit of activity 
$\cong 2.6 \times 10^{11}$ molecules of CAT enzyme protein. Acetylated products and the nonacetylated residues were separated on an Eastman Kodak silica gel TLC plate and, following autoradiography, were cut out and counted to determine the amount of acetylation. In some experiments injected embryo pellets were resuspended in $100 \mu \mathrm{l} 250 \mathrm{~mm}$ Tris- $\mathrm{HCl}(\mathrm{pH} 7.8)$, which also contained about 2000 uninjected $S$. purpuratus carrier embryos, and then lysed. Half of the lysate was used for assay of CAT enzyme protein content as described, and the remaining portion was stored at $-70^{\circ} \mathrm{C}$ for measurement of CAT DNA by the slot-blot hybridization procedure of Flytzanis et al. (1987) and Franks et al. (1987). Thus, the $50 \mu$ l lysate was mixed with an equal volume of a solution containing $0.1 \mathrm{M}$ EDTA ( $\mathrm{pH} 8.0$ ), 0.2 $\mathrm{M} \mathrm{NaCl}, 1 \%$ SDS, and $20 \mu \mathrm{g}$ of proteinase $\mathrm{K}$ and incubated for 2 $\mathrm{hr}$ at $55^{\circ} \mathrm{C}$. The nucleic acids were then extracted once in phenol/chloroform/isoamylalcohol $(25: 24: 1)$ and once in chloroform/isoamylalcohol $(24: 1)$. The total amount of DNA recovered was measured in an aliquot by the DAPI method, and the remaining solution was treated with $0.4 \mathrm{M} \mathrm{NaOH}$ at $65^{\circ} \mathrm{C}$ for $1 \mathrm{hr}$ to denature the DNA and hydrolyze the RNA, and filtered onto nitrocellulose using a Schleicher \& Schuell Minifold II slot-blot apparatus. The slots were bisected exactly in half, and separately hybridized with single-stranded RNA probes that were prepared from Sp6 vectors and contained sequences representing either the CAT gene or the single-copy $S$. purpuratus CyI actin gene sequence (Lee et al. 1984; Flytzanis et al. 1987). Probe-specific activities were about $1.3 \times 10^{9} \mathrm{cpm} / \mu \mathrm{g}$. The reaction of the CyI probe with the measured mass of $S$. purpuratus carrier embryo DNA per sample served as a hybridization efficiency standard. Hybridizations were carried out as described (Flytzanis et al. 1985, 1987), except that hybridizations with the CAT probe and $\mathrm{CyI}$ actin probe were at $40^{\circ} \mathrm{C}$ and $35^{\circ} \mathrm{C}$, respectively. The filters were washed twice with $2 \times \mathrm{SSC}$, $0.2 \%$ SDS at room temperature, twice with $2 \times$ SSC, $0.2 \%$ SDS at $60^{\circ} \mathrm{C}$, and twice with $1 \times$ SSC, $0.2 \%$ SDS at $60^{\circ} \mathrm{C}$. Following autoradiography each half-slot was excised and counted, and calculations were carried out exactly as described earlier (Flytzanis et al. 1987).

\section{In situ hybridizations with CAT antisense RNA probe}

The in situ hybridizations were also carried out essentially as described previously (Hough-Evans et al. 1987). Sea urchin embryos were fixed in $1 \%$ glutaraldehyde (Cox et al. 1984), and embryos were placed in $1 \%$ agarose boxes, which were then processed through an alcohol series to xylene, embedded in Paraplast (Monoject Scientific), and sectioned at $5 \mu \mathrm{m}$. Five-micrometer sections of plutei derived from uninjected eggs were included on each slide as controls. The $\left[{ }^{3} \mathrm{H}\right] \mathrm{RNA}$ CAT antisense probe was prepared from a 550-nucleotide BglII-Sall fragment of pSVO-CAT (Gorman et al. 1982) that had been inserted into the polylinker of pSP65 and transcribed, essentially as directed in the Promega Biotec protocol, using $\left[{ }^{3} \mathrm{H}\right] \mathrm{GTP}$ (sp. act., 33.9 $\mathrm{Ci} / \mathrm{mm}$ ) and $\left[{ }^{3} \mathrm{H}\right] \mathrm{UTP}$ (sp. act., $35.8 \mathrm{Ci} / \mathrm{mm}$ ). Probe specific activity was calculated to be about $1.18 \times 10^{8} \mathrm{dpm} / \mu \mathrm{g}$. The probe was hydrolyzed in bicarbonate buffer $(\mathrm{pH} \mathrm{10.2)} \mathrm{for} 45 \mathrm{~min}$ as recommended by Angerer and Angerer (1981). The $\left[{ }^{3} \mathrm{H}\right] \mathrm{RNA}$ CyIII 3' antisense probe reacted with the $S$. purpuratus pluteus controls in the experiments shown in Figure 3 was prepared from a 131-nucleotide pGEM subclone described by Lee et al. (1986). This probe was transcribed with T7 RNA polymerase and was used for hybridization without hydrolysis. The hybridization reactions and ancillary procedures were carried out by the methods of Angerer and Angerer (1981) and Cox et al. (1984). Slides were exposed for 4-10 weeks in sealed black plastic slide boxes containing desiccant, at $4^{\circ} \mathrm{C}$. The sections were not stained. They were observed and photographed under phase and darkfield microscopy.

\section{Acknowledgments}

This research was supported by National Institutes of Health grant HD-05753. R.R.F. was supported by an NIH postdoctoral training grant HD-07257.

\section{References}

Akhurst, R.J., F.J. Calzone, J.J. Lee, R.J. Britten, and E.H. Davidson. 1987. Structure and organization of the CyIII actin gene subfamily of the sea urchin, Strongylocentrotus purpuratus. I. Mol. Biol. 194: 193-203.

Angerer, L.M. and R.C. Angerer. 1981. Detection of poly(A) ${ }^{+}$ RNA in sea urchin eggs and embryos by quantitative in situ hybridization. Nucleic Acids Res. 9: 2819-2840.

Angerer, R.C. and E.H. Davidson. 1984. Molecular indices of cell lineage specification in sea urchin embryos. Science 226: $1153-1160$.

Angerer, R.C., E.H. Davidson, and R.J. Britten. 1976. Single copy DNA and structural gene sequence relationships among four sea urchin species. Chromosoma 56: 213-226.

Britten, R.J. and E.H. Davidson. 1971. Repetitive and nonrepetitive DNA sequences and a speculation on the origins of evolutionary novelty. Q. Rev. Biol. 46: 111-138.

Bruskin, A.M., A.L. Tyner, D.E. Wells, R.M. Showman, and W.H. Klein. 1981. Accumulation in embryogenesis of five mRNAs enriched in the ectoderm of the sea urchin pluteus. Dev. Biol. 87: 308-318.

Bruskin, A.M., P.A. Bedard, A.L. Tyner, R.M. Showman, B.P. Brandhorst, and W.H. Klein. 1982. A family of proteins accumulating in ectoderm of sea urchin embryos specified by two related cDNA clones. Dev. Biol. 91: 317-324.

Cameron, R.A., B.R. Hough-Evans, R.J. Britten, and E.H. Davidson. 1987. Lineage and fate of each blastomere of the eight-cell sea urchin embryo. Genes Dev. 1: 75-84.

Carpenter, C.D., A.M. Bruskin, P.E. Hardin, M.J. Keast, J. Anstrom, A.L. Tyner, B.P. Brandhorst, and W.H. Klein. 1984. Novel proteins belonging to the troponin $C$ superfamily are encoded by a set of mRNAs in sea urchin embryos. Cell 36: $663-671$.

Colin, A.M., T.L. Catlin, S.H. Kidson, and R. Maxson. 1987. Closely linked early and late $\mathrm{H} 2 \mathrm{~b}$ histone genes are differentially expressed after microinjection into sea urchin zygotes. Proc. Nat1. Acad. Sci. (in press).

Cox, K.H., D.V. DeLeon, L.M. Angerer, and R.C. Angerer. 1984. Detection of mRNAs in sea urchin embryos by in situ hybridization using asymmetric RNA probes. Dev. Biol. 101: 485-502.

Cox, K.H., L.M. Angerer, J.J. Lee, R.J. Britten, and E.H. Davidson. 1986. Cell lineage-specific programs of expression of multiple actin genes during sea urchin embryogenesis. $/$. Mol. Biol. 188: 159-172.

Crain, W.R. and F.D. Bushman. 1983. Transcripts of paternal and maternal actin gene alleles are present in interspecific sea urchin embryo hybrids. Dev. Biol. 100: 190-196.

Davidson, E.H. 1976. Gene activity in early development, 2nd ed. Academic Press, New York.

1982. Evolutionary change in genomic regulatory organization: Speculations on the origins of novel biological structure. In Evolution and development, Dahlem Konferenzen (ed. J.T. Bonner), pp. 65-84. Springer-Verlag, Berlin. 
1986. Gene activity in early development, 3rd ed. Academic Press, Orlando, Florida.

Davidson, E.H., C.N. Flytzanis, J.J. Lee, J.J. Robinson, S.J. Rose, and H.M. Sucov. 1985. Lineage-specific gene expression in the sea urchin embryo. Cold Spring Harbor Symp. Quant. Biol. 50: 321-328.

Flytzanis, C.N., A.P. McMahon, B.R. Hough-Evans, K.S. Katula, R.J. Britten, and E.H. Davidson. 1985. Persistence and integration of cloned DNA in postembryonic sea urchins. Dev. Biol. 108: $431-442$.

Flytzanis, C.N., R.J. Britten, and E.H. Davidson. 1987. Ontogenic activation of a fusion gene introduced into the sea urchin egg. Proc. Natl. Acad. Sci. 84: 151-155.

Franks, R.R., B.R. Hough-Evans, R.J. Britten, and E.H. Davidson. 1987. Direct introduction of cloned DNA into the sea urchin zygote nucleus, and fate of injected DNA. Development (in press).

Gorman, C.M., L.F. Moffat, and B.H. Howard. 1982. Recombinant genomes which express chloramphenicol acetyltransferase in mammalian cells. Mol. Cell. Biol. 2: 1044-1051.

Grula, J.W., T.J. Hall, J.A. Hunt, T.D. Guigni, E.H. Davidson, and R.J. Britten. 1982. Sea urchin DNA sequence polymorphism and reduced interspecies differences of the less polymorphic DNA sequences. Evolution 36: 665-676.

Hall, T.J., J.W. Grula, E.H. Davidson, and R.J. Britten. 1980. Evolution of sea urchin non-repetitive DNA. I. Mol. Evol. 16: $95-110$.

Hough-Evans, B.R., R.R. Franks, R.A. Cameron, R.J. Britten, and E.H. Davidson. 1987. Correct cell type-specific expression of a fusion gene injected into sea urchin eggs. Dev. Biol. 121: $576-579$.

Jensen, M. 1981. Morphology and classification of Euechinoidea Bronn, 1860: A cladistic analysis. Vidensk. Meddr. Dansk. Naturh. Foren. 143: 1-99.

Katula, K.S., B.R. Hough-Evans, R.J. Britten, and E.H. Davidson. 1987. Ontogenic expression of a CyI : actin fusion gene injected into sea urchin eggs. Development 101: 437-447.

Lee, J.J. 1986. "The genomic organization of the Strongylocentrotus purpuratus actin gene family." Ph.D. Thesis, California Institute of Technology.

Lee, J.J., R.J. Shott, S.J. Rose, T.L. Thomas, R.J. Britten, and E.H. Davidson. 1984. Sea urchin actin gene subtypes: Gene number, linkage, and evolution. J. Mol. Biol. 172: 149-176.

Lee, J.J., F.J. Calzone, R.J. Britten, R.C. Angerer, and E.H. Davidson. 1986. Activation of sea urchin actin genes during embryogenesis. Measurement of transcript accumulation from five different genes in Strongylocentrotus purpuratus. J. Mol. Biol. 188: 173-183.

Lynn, D.A., L.M. Angerer, A.M. Bruskin, W.H. Klein, and R.C. Angerer. 1983. Localization of a family of mRNAs in a single cell type and its precursor in sea urchin embryos. Proc. Natl. Acad. Sci. 80: 2656-2660.

McMahon, A.P., T.J. Novak, R.J. Britten, and E.H. Davidson. 1984. Inducible expression of a cloned heat shock fusion gene in sea urchin embryos. Proc. Natl. Acad. Sci. 81: $7490-7494$.

McMahon, A.P., C.N. Flytzanis, B.R. Hough-Evans, K.S. Katula, R.J. Britten, and E.H. Davidson. 1985. Introduction of cloned DNA into sea urchin egg cytoplasm: Replication and persistance during embryogenesis. Dev. Biol. 108: 420-430.

Shott, R.J., J.J. Lee, R.J. Britten, and E.H. Davidson. 1984. Differential expression of the actin gene family of Strongylocentrotus purpuratus. Dev. Biol. 101: 295-306. 


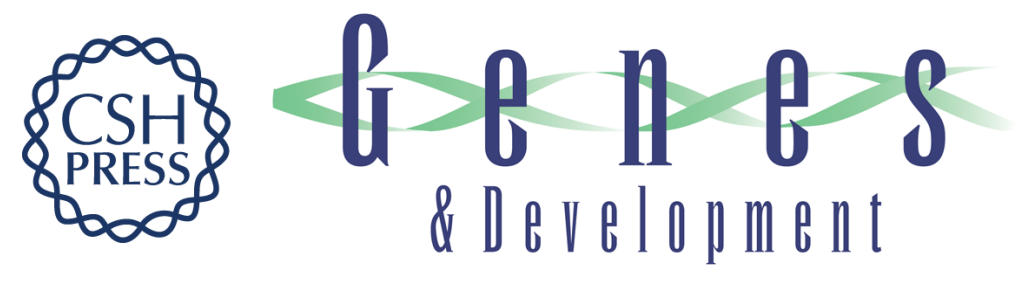

\section{Spatially deranged though temporally correct expression of Strongylocentrotus purpuratus actin gene fusion in transgenic embryos of a different sea urchin family.}

R R Franks, B R Hough-Evans, R J Britten, et al.

Genes Dev. 1988, 2:

Access the most recent version at doi:10.1101/gad.2.1.1

References This article cites 27 articles, 8 of which can be accessed free at:

http://genesdev.cshlp.org/content/2/1/1.full.html\#ref-list-1

License

Email Alerting Receive free email alerts when new articles cite this article - sign up in the box at the top

Service right corner of the article or click here.

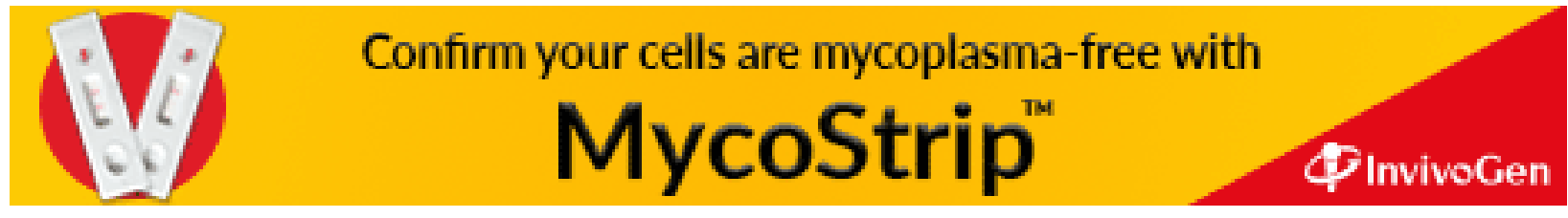

